\title{
AVALIAÇÃO DE CONTAMINAÇÃO POR ECHERICHIA COLI DA LINHA VERDE DA LAGOA DO MEIO, LINHARES-ES
}

\author{
Rafael Zucateli da Vitoria ${ }^{1}$ \\ Felipe de Tassio Gonçalves de Oliveira² \\ Stanley Bravo Buffon ${ }^{3}$ \\ Rafael Costa de Sant'Ana ${ }^{4}$ \\ Felipe Pereira Dal'Col ${ }^{5}$ \\ Renan Garcia Malikouski ${ }^{6}$ \\ Marcia Cristiane Kravetz Andrade ${ }^{7}$
}

Resumo: Atualmente os rios, lagos e lagoas, situados próximos às cidades estão recebendo altas cargas poluidoras. Devido estes fatores os eventos climáticos como chuvas e secas estão cada vez mais severos e as fontes hídricas saldáveis cada vez mais escassas, portanto, é muito importante manter os recursos hídricos limpos para em caso de necessidade hídrica poder contar com mais alternativas e fontes para capitação de água para consumo. Avaliou-se a localidade denominada Linha Verde da Lagoa do Meio no município de Linhares em relação à contaminação por Escherichia coli, sendo coletadas duas amostras de água da lagoa. Amostra 1 a montante da Linha Verde e Amostra 2 a jusante da Linha Verde e com base nos resultados obtidos a Lagoa do Meio está livre de contaminação por Escherichia coli na localidade da Linha Verde.

Palavras-chave: Escherichia; Contaminação; Poluição hídrica; Lago.

\footnotetext{
${ }^{1}$ Universidade Federal do Espírito Santo - UFES, Centro Universitário Norte do Espírito Santo - CEUNES, São Mateus, ES, Brasil. E-mail: zucateli_rafael@hotmail.com.

2 Instituto Capixaba de Pesquisa, Assistência Técnica e Extensão Rural - INCAPER, Centro Regional de Desenvolvimento Rural - Centro Norte, Laboratório de Fisiologia Vegetal e Pós-Colheita, Linhares, ES, Brasil. Email: felipe_dtassio@hotmail.com.

3 Instituto Capixaba de Pesquisa, Assistência Técnica e Extensão Rural - INCAPER, Centro Regional de Desenvolvimento Rural - Centro Norte, Laboratório de Fisiologia Vegetal e Pós-Colheita, Linhares, ES, Brasil. Email: acordatrevo@hotmail.com.

4 Instituto Capixaba de Pesquisa, Assistência Técnica e Extensão Rural - INCAPER, Centro Regional de Desenvolvimento Rural - Centro Norte, Laboratório de Fisiologia Vegetal e Pós-Colheita, Linhares, ES, Brasil. Email: santanaagronomia@gmail.com.

5 Instituto Federal do Espírito Santo - IFES, Campus Santa Teresa, Santa Teresa, ES, Brasil. E-mail: felipepdalcol@gmail.com.

6 Instituto Federal do Espírito Santo - IFES, Campus Santa Teresa, Santa Teresa, ES, Brasil. E-mail: renan_malikouski@hotmail.com.

7 Centro Universitário Internacional UNINTER, Pós-graduação em Educação Ambiental e Sustentabilidade, Unidade Ponta Grossa, Campo Largo, PR, Brasil. E-mail: marciacriskra@hotmail.com.
} 